\title{
Aplicação Simultânea de Dessecantes e Boro no Manejo de Plantas Daninhas e na Nutrição Mineral das Culturas de Soja e GIRASSOL $^{1}$
}

\author{
Simultaneous Application of Desiccants and Boron for Weed Control and Mineral Nutrition of \\ Soybean and Sunflower
}

BRIGHENTI, A.M. ${ }^{2}$, CASTRO, C. ${ }^{2}$, MENEZES, C.C. ${ }^{3}$, OLIVEIRA, F.A. ${ }^{2}$ e FERNANDES, P.B. ${ }^{4}$

\begin{abstract}
RESUMO - Dois experimentos foram conduzidos com o objetivo de avaliar o controle de plantas daninhas em pré-semeadura da soja (Glycine max) e do girassol (Helianthus annuus), por meio de aplicações de herbicidas dessecantes, isolados ou em combinação com boro, bem como a resposta dessas culturas à aplicação desse micronutriente. Nas parcelas de soja, foram aplicados os tratamentos glyphosate $(1,44 \mathrm{~kg}$ e.a. ha-1), glyphosate potássico $(2,48 \mathrm{~kg}$ i.a. ha-1), diuron $\left(0,2 \mathrm{~kg}\right.$ i.a. ha-1) + paraquat $\left(0,4 \mathrm{~kg}\right.$ i.a. ha $\left.\mathrm{h}^{-1}\right)$, e paraquat $\left(0,400 \mathrm{~kg}\right.$ i.a. ha- $\left.\mathrm{ha}^{-1}\right)$. Nas parcelas de girassol, foram aplicados os tratamentos glyphosate $(0,54 \mathrm{~kg}$ e.a. ha-1), glyphosate $\left(0,72 \mathrm{~kg}\right.$ e.a. ha-1), glyphosate potássico $\left(1,24 \mathrm{~kg}\right.$ i.a. ha-1), paraquat $\left(0,4 \mathrm{~kg}\right.$ i.a. ha- $\left.{ }^{-1}\right)$, glyphosate $\left(0,72 \mathrm{~kg}\right.$ e.a. ha $\left.{ }^{-1}\right)+$ flumioxazin $(0,025 \mathrm{~kg}$ i.a. ha-1) e glyphosate $(0,72 \mathrm{~kg}$ e.a. ha-1) + carfentrazone $\left(0,02 \mathrm{~kg}\right.$ i.a. ha $\left.{ }^{-1}\right)$. Ambos os experimentos continham as testemunhas capinada e sem capina. As subparcelas dos dois experimentos foram constituídas pela ausência ou presença de B, junto à calda de pulverização, na fonte ácido bórico $\left[\mathrm{H}_{3} \mathrm{BO}_{3}-17 \% \mathrm{~B}\right]$. A adição de ácido bórico à calda de pulverização não prejudicou o controle das plantas daninhas pelos tratamentos dessecantes, exceto para a mistura formulada de paraquat + diuron. Houve aumento dos teores de boro no solo e nas folhas da cultura da soja e do girassol quando foram associados os tratamentos com herbicidas dessecantes e o ácido bórico. É viável a aplicação de herbicidas dessecantes e ácido bórico, controlando as plantas daninhas em pré-semeadura e aumentando o teor de B no solo e nas plantas de soja e de girassol.
\end{abstract}

Palavras-chave: Glycine max, Helianthus annuus, controle químico, herbicidas, ácido bórico.

\begin{abstract}
Two experiments were carried out to evaluate weed control in soybean (Glycine max) and sunflower (Helianthus annuus) pre-sowing by desiccant application alone or in combination with boron (B), as well as to evaluate the response of these crops to that micronutrient. The plots consisted of the desiccants glyphosate (1.44 $\mathrm{kg}$ a.e. ha-1), glyphosate potassium (2.48 $\mathrm{kg}$ a.i. $\mathrm{ha^{-1 }}$ ), diuron $\left(0.2 \mathrm{~kg}\right.$ a.i. $\left.\mathrm{ha}^{-1}\right)$ plus paraquat $\left(0.4 \mathrm{~kg}\right.$ a.i.ha $\left.\mathrm{a}^{-1}\right)$, paraquat $\left(0.4 \mathrm{~kg}\right.$ a.i. $\left.\mathrm{ha}^{-1}\right)$ in the soybean experiment. In the sunflower experiment, the plots consisted of glyphosate $\left(0.54 \mathrm{~kg}\right.$ a.e. $\left.h \mathrm{~h}^{-1}\right)$, glyphosate $\left(0.72 \mathrm{~kg}\right.$ a.e. $\left.\mathrm{ha}^{-1}\right)$, glyphosate potassium (1.24 kg a.i. ha $\left.\mathrm{k}^{-1}\right)$, paraquat $\left(0.4 \mathrm{~kg}\right.$ a.i.ha $\left.\mathrm{h}^{-1}\right)$, glyphosate $\left(0.72 \mathrm{~kg}\right.$ a.e $\left.\mathrm{ha}^{-1}\right)$ plus flumioxazin $\left(0.025 \mathrm{~kg}\right.$ a.i. ha $\left.\mathrm{h}^{-1}\right)$, glyphosate

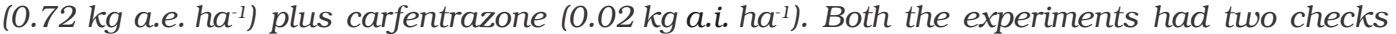
(hand-hoeing and weedy control) and the split-plots consisted of absence or presence of boron from boric acid $\left[\mathrm{H}_{3} \mathrm{BO}_{3}-17 \% \mathrm{~B}\right]$, associated to the water carrier. The combination of herbicides with boron efficiently controlled the weeds, except for paraquat plus diuron. The application of boric acid in association with herbicides increased the content of this micronutrient in the soil and consequently in the soybean and sunflower leaves. The combined application of desiccants and boric acid appears to be suitable for controlling weeds and increases mineral nutrition of soybean and sunflower.
\end{abstract}

Keywords: Glycine max, Helianthus annuus, chemical control, herbicides, boric acid.

Recebido para publicação em 13.4.2006 e na forma revisada em 10.11.2006.

Pesquisador da Embrapa Soja, Caixa Postal 231, 86001-970 Londrina-PR. ${ }^{3}$ Gerente do Centro Tecnológico da Comigo. ${ }^{4}$ Estagiária da Embrapa Soja/UEL/CNPq. 


\section{INTRODUÇÃO}

O boro (B) é um micronutriente essencial ao crescimento e desenvolvimento das plantas. Entretanto, seu teor nos solos brasileiros é geralmente baixo, e a falta desse micronutriente tem levado ao aparecimento de sintomas de deficiência em diversas culturas (Silva \& Ferreyra, 1998). Como esse micronutriente é pouco móvel na maioria das plantas, os sintomas de deficiência se manifestam primeiramente nas folhas jovens, que desenvolvem má formação, tornam-se duras e adquirem coloração bronzeada (Blamey et al., 1979; Blamey et al., 1997; Asad, 2002).

A falta de $B$ resulta em inibição do crescimento das plantas, devido ao fato de esse micronutriente fazer parte da estrutura da parede celular. Na sua ausência, ocorre redução na síntese de pectina, celulose e lignina na parede das células do lenho, tornando-as mais finas (Epstein \& Bloom, 2005). Também pode ocorrer inibição da elongação das raízes, em razão de distúrbios que ocorrem na divisão celular e na elongação das células (Marschner, 1995).

Esses fenômenos bioquímicos e fisiológicos se traduzem, em campo, na possibilidade de quebra das plantas e redução da produtividade (Castro, 1999; Castro \& Oliveira, 2005).

Em relação à soja, plantas deficientes em boro apresentam clorose internerval nas folhas mais novas, que se tornam coriáceas, com as pontas curvadas para baixo e com o limbo enrugado. Pode ocorrer morte da gema apical, havendo como conseqüência a ramificação do caule. As raízes têm crescimento limitado e as plantas apresentam nanismo, poucas folhas e pequeno pegamento de vagens (Rosolem et al., 2001).

No caso do girassol, quando comparado à soja e a outras culturas, há requerimento de maiores quantidades de B para satisfazer suas necessidades metabólicas (Castro \& Oliveira, 2005). O estádio reprodutivo do girassol é mais sensivel do que o vegetativo, em condições de baixo suprimento de B no solo (Castro et al., 1996; Asad et al., 2002). Plantas adultas com deficiência de B apresentam capítulos deformados ou com a região central com aquênios chochos, com menor número e/ou peso. Em casos extremos, pode ocorrer a queda do capítulo e conseqüente redução do rendimento.

A aplicação de $\mathrm{B}$ via solo, utilizando adubos com mistura de grânulos contendo o micronutriente, apresenta a desvantagem de promover segregação entre a fonte de B e os demais componentes do fertilizante, durante a mistura e o manuseio. A segregação interfere na uniformidade da aplicação de boro no solo devido, principalmente, à aplicação de baixas quantidades desse micronutriente (Mortvedt \& Woodruff, 1993).

A adubação foliar também é utilizada (Diggs et al., 1992; Asad et al., 2003). Entretanto, além de ser uma prática polêmica, tendo em vista os resultados controversos, ela aumenta os custos de produção, o nivel de compactação do solo e a quebra de plantas, em razão da passagem de máquinas pela área de cultivo. Também deve ser considerada a baixa mobilidade do B no floema, sendo necessárias várias aplicações do produto para suprir, mesmo em parte, a necessidade de B para os tecidos novos e os órgãos de reprodução.

Outro fator que interfere na produtividade das culturas é a ocorrência de plantas daninhas. A presença dessas espécies infestantes, durante as fases iniciais de desenvolvimento das culturas, resulta em plantas cloróticas, de menor porte, com severa diminuição da área foliar. Em relação à produtividade, muitos autores têm medido a magnitude das perdas, chegando a valores que variam de 82 a 96\% na cultura da soja e 23 a $70 \%$ na cultura do girassol (Vidal \& Merotto Jr., 2001). Dos componentes de rendimento do girassol, o mais afetado com a infestação de plantas daninhas é o número de aquênios por capítulo (Bedmar et al., 1983; Brighenti et al., 2005).

Assim, uma das maneiras de reduzir os custos de produção seria controlar as plantas daninhas e fornecer boro às plantas em uma única operação.

O objetivo dos experimentos foi avaliar o controle de plantas daninhas em pré-semeadura da soja e do girassol, por meio de aplicações de herbicidas dessecantes, isolados ou em combinação com boro, bem como a resposta 
dessas culturas à aplicação desse micronutriente.

\section{MATERIAL E MÉTODOS}

Foram conduzidos dois experimentos: um em Rio Verde, GO, com a cultura da soja, e outro em Chapadão do Sul, MS, com a cultura do girassol. Os resultados da análise química dos solos são apresentados na Tabela 1.

Antes da aplicação dos tratamentos, foi determinado o pH das caldas (Tabela 2).

\section{Experimento com a cultura da soja}

O experimento foi conduzido durante o ano agrícola 2004/2005, em área do Centro Tecnológico da Cooperativa Comigo, em Rio Verde-GO.
O delineamento experimental foi o de blocos casualizados em parcelas subdivididas, com quatro repetições. Nas parcelas, foram aplicados os tratamentos glyphosate $(1,44 \mathrm{~kg}$ e.a. ha-1), glyphosate potássico $\left(2,48 \mathrm{~kg}\right.$ i.a. ha- $\left.\mathrm{ha}^{-1}\right)$, diuron $(0,2 \mathrm{~kg}$ i.a. ha-1) + paraquat $(0,4 \mathrm{~kg}$ i.a. ha-1), paraquat $\left(0,4 \mathrm{~kg}\right.$ i.a. ha $\left.{ }^{-1}\right)$, a testemunha capinada e a sem capina. As subparcelas foram constituídas pela presença ou ausência de $1,0 \mathrm{~kg} \mathrm{ha}^{-1}$ de B, junto à calda de pulverização, na fonte ácido bórico $\left(\mathrm{H}_{3} \mathrm{BO}_{3}-17 \%\right.$ de $\left.\mathrm{B}\right)$.

As plantas daninhas predominantes foram cordão-de-frade (Leonotis nepetifolia), milho voluntário (Zea mays), joá-de-capote (Nicandra physaloides), trapoeraba (Commelina benghalensis), corda-de-viola (Ipomoea grandifolia) e capim-carrapicho (Cenchrus echinatus), as quais totalizavam, em média, 45 plantas por $\mathrm{m}^{2}$.

Tabela 1 - Análise química do solo na camada de 0 a $10 \mathrm{~cm}$ de profundidade nos experimentos conduzidos em Rio Verde, com a cultura da soja, e em Chapadão do Sul, com o girassol. Embrapa Soja, Londrina-PR, 2006 ${ }^{1 /}$

\begin{tabular}{|l|c|c|c|c|c|c|c|c|c|c|c|c|}
\hline \multirow{2}{*}{ Local } & $\mathrm{B}$ & $\mathrm{P}$ & $\mathrm{pH}$ & $\mathrm{Al}$ & $\mathrm{K}$ & $\mathrm{Ca}$ & $\mathrm{Mg}$ & $\mathrm{H}^{+}+\mathrm{Al}^{+3}$ & $\mathrm{SB}$ & $\mathrm{CTC}$ & $\mathrm{V}$ & $\mathrm{C}$ \\
\cline { 2 - 13 } & \multicolumn{10}{|c|}{$\left(\mathrm{mg} \mathrm{dm}^{-3}\right)$} & $\left(\mathrm{CaCl}_{2}\right)$ & \multicolumn{7}{|c|}{$\left(\mathrm{cmol}_{\mathrm{c}} \mathrm{dm}^{-3}\right)$} & & $(\%)$ & $\left(\mathrm{g} \mathrm{dm}^{-3}\right)$ \\
\hline Rio Verde & 0,21 & 13,1 & 5,0 & 0,0 & 0,12 & 3,39 & 0,78 & 3,92 & 4,3 & 8,2 & 52,0 & 22,2 \\
\hline Chapadão do Sul & 0,19 & 16,8 & 5,2 & 0,0 & 0,13 & 4,58 & 1,37 & 3,96 & 6,0 & 10,0 & 60,3 & 27,0 \\
\hline
\end{tabular}

${ }^{1 /}$ Resultados fornecidos pelo Laboratório de Análise de Solo e Tecido Vegetal da Embrapa Soja, Londrina-PR.

Tabela 2 - Valores de $\mathrm{pH}$ de caldas de pulverização, determinados antes da aplicação, em função das doses dos herbicidas aplicados isoladamente ou em combinação com ácido bórico. Embrapa Soja, Londrina-PR, 2006

\begin{tabular}{|c|c|c|c|c|c|}
\hline \multicolumn{3}{|c|}{ Experimento com soja } & \multicolumn{3}{|c|}{ Experimento com girassol } \\
\hline Tratamento & $\begin{array}{c}\text { Ácido bórico sem } \\
\text { ou com }\end{array}$ & $\mathrm{pH}$ & Tratamento & $\begin{array}{c}\text { Ácido bórico sem } \\
\text { ou com }\end{array}$ & $\mathrm{pH}$ \\
\hline Glyphosate & - & 4,75 & Glyphosate & - & 4,78 \\
\hline$\left(1,44\right.$ kg e.a. ha $\left.{ }^{-1}\right)$ & Ácido bórico & 4,54 & $\left(0,54 \mathrm{~kg}\right.$ e.a. ha $\left.{ }^{-1}\right)$ & Ácido bórico & 4,45 \\
\hline Glyphosate Potássico & - & 4,71 & Glyphosate & - & 4,55 \\
\hline$\left(2,48 \mathrm{~kg}\right.$ i.a. ha $\left.{ }^{-1}\right)$ & Ácido bórico & 4,48 & $\left(0,72\right.$ kg e.a. ha $\left.{ }^{-1}\right)$ & Ácido bórico & 4,20 \\
\hline Diuron + paraquat & - & 7,20 & Glyphosate Potássico & - & 4,85 \\
\hline$\left(0,2+0,4\right.$ kg i.a. ha $\left.{ }^{-1}\right)$ & Ácido bórico & 4,51 & $\left(1,24\right.$ kg i.a. ha $\left.{ }^{-1}\right)$ & Ácido bórico & 4,55 \\
\hline Paraquat & - & 6,75 & Paraquat & - & 6,80 \\
\hline$\left(0,4\right.$ kg i.a. ha $\left.{ }^{-1}\right)$ & Ácido bórico & 5,08 & $\left(0,4\right.$ kg i.a. ha $\left.{ }^{-1}\right)$ & Ácido bórico & 5,00 \\
\hline \multirow{2}{*}{ Testemunha (água) } & - & 6,70 & Glyphosate + Flumioxazin & - & 4,90 \\
\hline & Ácido bórico & 4,75 & $0,72 \mathrm{~kg}$ e. a. ha ${ }^{-1}+0,025 \mathrm{~kg}$ i.a. ha ${ }^{-1}$ & Ácido bórico & 4,31 \\
\hline & & & Glyphosate + Carfentrazone & - & 4,86 \\
\hline & & & 0,720 kg e. a. ha ${ }^{-1}+0,02 \mathrm{~kg}$ i.a. ha ${ }^{-1}$ & Ácido bórico & 4,43 \\
\hline & & & \multirow{2}{*}{ Testemunha (água) } & - & 6,88 \\
\hline & & & & Ácido bórico & 4,42 \\
\hline
\end{tabular}


A aplicação dos tratamentos foi feita em 2.12.2004, utilizando pulverizador costal, à pressão constante de $193 \mathrm{kPa}$, mantida por $\mathrm{CO}_{2}$ comprimido, equipado com barra de 1,5 m de largura e quatro bicos de jato plano $110015 \mathrm{BD}$, distanciados de $0,5 \mathrm{~m}$, com volume de pulverização equivalente a $160 \mathrm{~L} \mathrm{ha}^{-1}$.

A soja, cultivar Conquista, foi semeada em 9.12.2004, no espaçamento de 0,50 m entre fileiras e 15 sementes por metro. A adubação de semeadura foi de $250 \mathrm{~kg} \mathrm{ha}^{-1}$ da formulação N-P-K (00-20-20). A pluviosidade total ocorrida durante o ciclo da soja foi de $809 \mathrm{~mm}$.

A área das parcelas foi de $48 \mathrm{~m}^{2}$ (6 x $\left.8 \mathrm{~m}\right)$; a das subparcelas, de $24 \mathrm{~m}^{2}$ (3 $8 \mathrm{~m}$ ); e a área útil, de $7 \mathrm{~m}^{2}(1 \times 7 \mathrm{~m})$.

A porcentagem de controle das plantas daninhas foi avaliada aos 25 dias após a aplicação dos tratamentos (DAA), utilizando escala visual, em que 0\% correspondeu a nenhum controle e 100\% à morte das plantas daninhas.

Para análise do teor de boro, as folhas da soja foram amostradas em 10 plantas no início do florescimento coletando a terceira ou quarta folha, a partir do ápice. Em seguida, foram retiradas amostras de solo de cada subparcela, na profundidade de 0 a $10 \mathrm{~cm}$, para análise dos teores de boro. A produtividade foi obtida colhendo as plantas na área útil das subparcelas, com posterior transformação para $\mathrm{kg} \mathrm{ha}{ }^{-1}$, considerando a umidade em 13\%.

\section{Experimento com a cultura do girassol}

O experimento foi conduzido durante o ano agrícola 2003/2004 em Chapadão do Sul-MS, num Latossolo Vermelho-Amarelo.

O delineamento experimental foi o de blocos casualizados em parcelas subdivididas, com quatro repetições. Nas parcelas, foram aplicados os tratamentos glyphosate $(0,54 \mathrm{~kg}$ e.a. ha-1), glyphosate $(0,72 \mathrm{~kg}$ e.a. ha-1), glyphosate potássico $(1,24 \mathrm{~kg}$ i.a. ha-1), paraquat $\left(0,4 \mathrm{~kg}\right.$ i.a. ha-1), glyphosate $\left(0,72 \mathrm{~kg}\right.$ e.a. ha $\left.{ }^{-1}\right)$ + flumioxazin $(0,025 \mathrm{~kg}$ i.a. ha-1), glyphosate $\left(0,72 \mathrm{~kg}\right.$ e.a. $\left.\mathrm{ha}^{-1}\right)+$ carfentrazone $(0,02 \mathrm{~kg}$ i.a. ha-1) e duas testemunhas (capinada e sem capina). As subparcelas foram constituídas pela ausência ou presença de $B$, na calda de pulverização. Todos os tratamentos com herbicidas dessecantes foram aplicados, isolados ou em mistura, com $2 \mathrm{~kg} \mathrm{ha}^{-1}$ de B (ácido bórico $-\mathrm{H}_{3} \mathrm{BO}_{3}-17 \%$ de $\mathrm{B}$ ).

As plantas daninhas predominantes foram a trapoeraba (Commelina benghalensis) e o picão-preto (Bidens spp.), totalizando, em média, 4 plantas por $\mathrm{m}^{2}$.

A aplicação dos herbicidas foi feita em 5.3.2004. Foi utilizado pulverizador costal, à pressão constante de $276 \mathrm{kPa}$, mantida por $\mathrm{CO}_{2}$ comprimido, equipado com barra de $3,0 \mathrm{~m}$ de largura e sete bicos de jato plano 11003 XR, distanciados de $0,5 \mathrm{~m}$, com volume de pulverização equivalente a $250 \mathrm{~L} \mathrm{ha}^{-1}$.

O girassol, híbrido Helio 251, foi semeado em 8.3.2004 no espaçamento de $0,80 \mathrm{~m}$ entre fileiras, com densidade de 50 mil plantas por hectare. A adubação de semeadura foi constituída de $300 \mathrm{~kg} \mathrm{ha}^{-1}$ de N-P-K (formulação 5-20-20). Aos 30 dias após a semeadura, foi realizada uma adubação de cobertura com $40 \mathrm{~kg}$ de nitrogênio por hectare. A pluviosidade total ocorrida durante o ciclo do girassol foi de $332 \mathrm{~mm}$. A área das parcelas foi de $64 \mathrm{~m}^{2}$ (8,0 x $8 \mathrm{~m})$; a das subparcelas, de $32,0 \mathrm{~m}^{2}(4,0$ x 8,0 m); e a área útil, de 14,4 $\mathrm{m}^{2}$ (2,4 x $\left.6 \mathrm{~m}\right)$.

A porcentagem de controle das plantas daninhas foi avaliada aos 25 e 35 DAA dos tratamentos, utilizando a mesma escala visual descrita para o experimento com soja. Foram obtidos os valores médios da altura das plantas de girassol e do diâmetro do caule, a partir da medição de dez plantas escolhidas ao acaso, dentro da área útil de cada subparcela. Também foi avaliado o peso de mil aquênios. A terceira ou quarta folha, a partir do ápice das plantas de girassol, foram amostradas no início do florescimento $\left(\mathrm{R}_{5}\right)$, para análise do teor de boro. Em seguida, foram retiradas amostras de solo (0 a $10 \mathrm{~cm}$ de profundidade) de cada subparcela, também para análise dos teores de boro. O teor de óleo foi determinado por meio de ressonância magnética nuclear. A produtividade da cultura foi obtida colhendo três linhas de girassol, com 6 m de comprimento, na área útil das subparcelas, considerando em 11\% a umidade de aquênios.

Nos dois experimentos, os dados foram submetidos à análise de variância e as médias comparadas pelo teste de Tukey a 5\% de probabilidade. 


\section{RESULTADOS E DISCUSSÃO}

Nos experimentos com soja e girassol foram aplicados 5,8 e 11,7 kg de ácido bórico por hectare, que solubilizaram totalmente nos volumes utilizados: 160 e $250 \mathrm{~L} \mathrm{ha}^{-1}$, respectivamente. Essas quantidades dissolveram-se em água à temperatura aproximada de $25^{\circ} \mathrm{C}$, sem problemas de formação de precipitados, capazes de provocar o entupimento dos bicos de pulverização.

\section{Experimento com a cultura da soja}

As porcentagens de controle das plantas daninhas foram acima de 91\% nos tratamentos com glyphosate e glyphosate potássico com e sem ácido bórico (Tabela 3). A adição de B à calda de pulverização não interferiu no controle das plantas daninhas quando comparada a aplicação isolada dos dois herbicidas. No caso do glyphosate, a sua eficácia no controle de espécies daninhas é afetada pelas mudanças no $\mathrm{pH}$ da calda de pulverização (Turner \& Loader, 1978). As constantes de dissociação desse herbicida variam de 2,2 a 2,3 (grupo carboxílico - $\mathrm{pK}_{1}$ ), 5,5 a 5,9 (grupamento fosfônico - $\mathrm{pK}_{2}$ ) e 10,1 a 10,9 (grupamento amino $\mathrm{pK}_{3}$ ) (Wauchope, 1976). Segundo Motekaitis \& Martell (1985), uma variação do pH da solução de glyphosate de 2 para 11 resulta numa sucessiva desprotonação do grupo carboxílico, seguida do grupamento fosfônico e, finalmente, do grupamento amino.

Os valores de $\mathrm{pH}$ das caldas de pulverização para os herbicidas isolados e combinados com o ácido bórico são apresentados na Tabela 2. Ao adicionar o glyphosate à água, ocorreu redução do $\mathrm{pH}$ da calda, que passou de 6,7 para 4,7, em média. Essa diminuição foi ainda mais acentuada ao se adicionar $\mathrm{B}$ à fonte ácido bórico (pH a 4,4). Nessa condição, predomina a forma não-iônica das moléculas desse herbicida, que possui características apolares e rapidamente passa através da membrana plasmática das células. Dentro da planta, as cargas da molécula do glyphosate podem mudar, dependendo se a molécula estiver no apoplasto $(\mathrm{pH}=5,0)$ ou no simplasto $(\mathrm{pH}=$ 7,5) (Sterling, 1994).

Brighenti et al. (2004) observaram que, ao se adicionarem outras fontes de B, como os poliboratos (Solubor, Inkabor ou Bórax), à calda com glyphosate, ocorre elevação do pH, reduzindo a eficácia desse herbicida no controle das plantas daninhas, principalmente nas avaliações iniciais de controle. Em soluções alcalinas, além de a molécula do glyphosate ter maior dificuldade, em termos de absorção,

Tabela 3 - Percentagens de controle de plantas daninhas aos 25 dias após a aplicação dos tratamentos, teores de boro no solo $\left(\mathrm{mg} \mathrm{dm}^{-3}\right)$ (profundidade de $\left.0-10 \mathrm{~cm}\right)$, teores de boro nas folhas $\left(\mathrm{mg} \mathrm{kg}^{-1}\right)$ e rendimento da cultura da soja $\left(\mathrm{kg} \mathrm{ha}^{-1}\right)$, em função dos tratamentos, na ausência (sem) ou na presença (com) de boro. Embrapa Soja, Londrina-PR, 2006

\begin{tabular}{|c|c|c|c|c|c|}
\hline Tratamento & Boro & Controle & B no solo & B na folha & Rendimento \\
\hline \multirow{2}{*}{ Glyphosate $\left(1,44 \mathrm{~kg}\right.$ e.a. $\left.\mathrm{ha}^{-1}\right)$} & sem & $93,7 \mathrm{~A}^{\mathrm{1} /}$ & $0,22 \mathrm{~A}$ & $41,4 \mathrm{~B}$ & $2.105,6 \mathrm{~A}$ \\
\hline & com & $91,2 \mathrm{~A}$ & $0,25 \mathrm{~A}$ & $48,1 \mathrm{~A}$ & $2.185,0 \mathrm{~A}$ \\
\hline \multirow{2}{*}{ Glyphosate potássico $\left(2,48 \mathrm{~kg}\right.$ i.a. $\left.\mathrm{ha}^{-1}\right)$} & sem & $92,5 \mathrm{~A}$ & $0,19 \mathrm{~B}$ & $39,1 \mathrm{~B}$ & $2.034,6 \mathrm{~A}$ \\
\hline & com & $92,5 \mathrm{~A}$ & $0,24 \mathrm{~A}$ & $48,9 \mathrm{~A}$ & $2.247,4 \mathrm{~A}$ \\
\hline \multirow{2}{*}{ Paraquat + Diuron $\left(0,2+0,4\right.$ kg i.a. ha $\left.^{-1}\right)$} & sem & $75,0 \mathrm{~A}$ & $0,20 \mathrm{~B}$ & $40,2 \mathrm{~B}$ & $1.922,7 \mathrm{~A}$ \\
\hline & com & $65,0 \mathrm{~B}$ & $0,25 \mathrm{~A}$ & $47,5 \mathrm{~A}$ & $1.951,1 \mathrm{~A}$ \\
\hline \multirow{2}{*}{ Paraquat $\left(0,4\right.$ kg i.a. ha $\left.{ }^{-1}\right)$} & sem & $76,2 \mathrm{~A}$ & $0,22 \mathrm{~B}$ & $40,9 \mathrm{~B}$ & $2.013,5 \mathrm{~A}$ \\
\hline & com & $78,7 \mathrm{~A}$ & $0,28 \mathrm{~A}$ & $47,8 \mathrm{~A}$ & $1.988,0 \mathrm{~A}$ \\
\hline \multirow{2}{*}{ Testemunha capinada } & sem & $100,0 \mathrm{~A}$ & $0,21 \mathrm{~B}$ & $42,3 \mathrm{~B}$ & $2.101,9 \mathrm{~A}$ \\
\hline & com & $100,0 \mathrm{~A}$ & $0,26 \mathrm{~A}$ & $48,1 \mathrm{~A}$ & $2.106,3 \mathrm{~A}$ \\
\hline \multirow{2}{*}{ Testemunha sem capina } & sem & $0,0 \mathrm{~A}$ & $0,21 \mathrm{~B}$ & $44,4 \mathrm{~A}$ & $1.164,5 \mathrm{~A}$ \\
\hline & com & $0,0 \mathrm{~A}$ & $0,28 \mathrm{~A}$ & $44,5 \mathrm{~A}$ & $1.004,5 \mathrm{~A}$ \\
\hline $\mathrm{CV}(\%)$ & - & 6,5 & 10,5 & 5,5 & 12,0 \\
\hline
\end{tabular}

${ }^{1 /}$ Médias seguidas pelas mesmas letras, na coluna e para cada tratamento, não diferem entre si pelo teste de Tukey a $5 \%$ de probabilidade. 
devido à baixa permeabilidade da membrana a ânions mono e divalentes (Gougler \& Geiger, 1981), ocorre também repulsão das moléculas desse herbicida. Isso acontece devido ao potencial elétrico negativo da membrana, reduzindo sua entrada e o acúmulo no citoplasma (Sterling, 1994). Stahlman \& Phillips (1979) também verificaram que, à medida que a calda de pulverização se torna mais alcalina, decresce a atividade do glyphosate. A forma com dupla ionização fica, ainda, sujeita à interação com possiveis cátions em solução, como o $\mathrm{Ca}^{+2}$ e o $\mathrm{Mg}^{+2}$ (Thelen et al., 1995), reduzindo a ação do herbicida.

É provável também que a absorção do glyphosate através da membrana plasmática seja mediada por um carregador de fosfato $\left(\mathrm{H}_{2} \mathrm{PO}_{4}^{-}\right)$(Denis \& Delrot, 1993; Sterling, 1994) e que, havendo predominância de formas mono e divalentes, em condições mais alcalinas, maior será a dificuldade de penetração através de barreiras carregadas negativamente, como a dupla camada fosfolipídica da membrana das células.

Em relação aos tratamentos com paraquat e paraquat + diuron, isolado ou em combinação com o ácido bórico, as porcentagens de controle foram baixas $(<78 \%)$. Além disso, a adição do ácido bórico à calda de pulverização interferiu na eficácia da mistura formulada de paraquat + diuron sobre as espécies daninhas (Tabela 3). A adição do ácido bórico à calda de paraquat + diuron reduziu o $\mathrm{pH}$, passando de 7,2 para 4,5 (Tabela 2). No caso do paraquat, provavelmente, esse fato não afetou a eficácia desse herbicida, por ele ser mais estável em soluções neutras e ácidas (Inchem, 2005). Entretanto, o diuron é mais estável em pH neutro (Lucy, 2005) e a redução do $\mathrm{pH}$ pode ter prejudicado sua eficácia quando em mistura com o ácido bórico.

Quando foram aplicados os tratamentos sem ácido bórico, os teores de B no solo foram, em média, de 0,20 $\mathrm{mg} \mathrm{dm}^{-3}$, ao passo que, nos tratamentos em que houve adição dessa fonte de boro, os valores atingiram 0,26 $\mathrm{mg} \mathrm{dm}^{-3}$ (Tabela 3). Com o aumento de B no solo, houve absorção de maior quantidade do micronutriente pelas raízes e, conseqüentemente, foi verificado maior teor nas folhas. Nos tratamentos sem B, o teor de boro nas folhas foi, em média, de 41,4 mg kg-1; naqueles com adição do ácido bórico, esse valor passou para 47,48 $\mathrm{mg} \mathrm{kg}^{-1}$.

A adição de boro à calda de pulverização não resultou em aumentos significativos dos rendimentos de grãos da soja. Isso se deve ao fato de que, mesmo nos tratamentos sem boro, os teores de B nas folhas alcançaram níveis considerados adequados à cultura. Entretanto, Sarker et al. (2002) constataram que a adição de $1 \mathrm{~kg}$ de $\mathrm{B} \mathrm{ha}^{-1}$ proporcionou aumentos consideráveis nos teores de óleo e de proteína, no número de vagens e sementes por planta, bem como na produtividade da cultura da soja.

\section{Experimento com a cultura do girassol}

Todos os tratamentos apresentaram valores de porcentagem de controle das plantas daninhas acima de 86 e 90\%, aos 25 e 35 DAA, respectivamente (Tabela 4 ).

Quando os tratamentos foram aplicados isoladamente, os teores de $\mathrm{B}$ na camada de solo de $0-10 \mathrm{~cm}$ atingiram valores médios de $0,18 \mathrm{mg} \mathrm{dm}^{-3}$. No entanto, quando os mesmos tratamentos foram aplicados em associação com boro, o valor médio foi de $0,32 \mathrm{mg} \mathrm{dm}^{-3}$.

Em relação aos teores de boro nas folhas do girassol, houve incremento considerável desses valores, passando de $34,70 \mathrm{mg} \mathrm{kg}^{-1}$, nos tratamentos aplicados isoladamente, para $55,25 \mathrm{mg} \mathrm{kg}^{-1}$ naqueles em que houve associação de boro à calda de pulverização. Este valor está bem acima daqueles considerados adequados para o girassol por Blamey (1976) e Machado (1979), cujos teores foram de 47 e $50 \mathrm{mg} \mathrm{kg}^{-1}$, respectivamente.

No que se refere às variáveis, altura de plantas, diâmetro de caule, peso de mil aquênios, teor de óleo e rendimento de grãos de girassol, não houve diferença estatística entre os tratamentos. Boaretto et al. (1997) verificaram que muitas vezes a não-correlação entre os aumentos dos teores de boro nas folhas e a produtividade das culturas pode ser explicada pela dificuldade da planta em remover esse micronutriente retido na cutícula foliar ou aquele ligado à camada péctica da parede celular e transferi-lo para os grãos. Há também a possibilidade de haver outro fator limitante ao rendimento de grãos de girassol que não seja a disponibilidade de boro. 
Tabela 4 - Porcentagens de controle geral de plantas daninhas aos 25 e 35 dias após a aplicação dos herbicidas, teor de B na camada de solo de 0-10 $\mathrm{cm}\left(\mathrm{mg} \mathrm{dm}^{-3}\right)$, teor de B nas folhas $\left(\mathrm{mg} \mathrm{kg}^{-1}\right)$, altura de plantas $(\mathrm{cm})$, diâmetro de caule $(\mathrm{mm})$, peso de 1.000 aquênios $(\mathrm{g})$, teor de óleo $(\%)$ e produtividade da cultura do girassol $\left(\mathrm{kg} \mathrm{ha}^{-1}\right)$, em função dos tratamentos. Embrapa Soja, Londrina-PR, 2006

\begin{tabular}{|c|c|c|c|c|c|c|c|c|c|c|}
\hline \multirow{2}{*}{ Tratamento } & \multirow{2}{*}{$\begin{array}{c}\text { Fontes de } \\
\text { B }\end{array}$} & \multicolumn{2}{|c|}{ Controle } & \multirow{2}{*}{$\begin{array}{c}\text { Boro no } \\
\text { solo }\end{array}$} & \multirow{2}{*}{$\begin{array}{l}\text { Boro na } \\
\text { folha }\end{array}$} & \multirow{2}{*}{ Altura } & \multirow{2}{*}{$\begin{array}{l}\text { Diâmetro } \\
\text { do caule }\end{array}$} & \multirow{2}{*}{$\begin{array}{l}\text { Peso } 1.000 \\
\text { aquênios }\end{array}$} & \multirow{2}{*}{$\begin{array}{l}\text { Teor de } \\
\text { óleo }\end{array}$} & \multirow{2}{*}{$\begin{array}{c}\text { Produti- } \\
\text { vidade }\end{array}$} \\
\hline & & 25 & 35 & & & & & & & \\
\hline Glyphosate & - & $86,2 \mathrm{~A}^{\mathrm{1} /}$ & $90,7 \mathrm{~A}$ & $0,20 \mathrm{~B}$ & $46,6 \mathrm{~B}$ & $193,3 \mathrm{~A}$ & $22,8 \mathrm{~A}$ & $40,6 \mathrm{~A}$ & $35,5 \mathrm{~A}$ & $1.727,9 \mathrm{~A}$ \\
\hline$\left(0,54 \mathrm{~kg}\right.$ e.a. $\left.\mathrm{ha}^{-1}\right)$ & $\begin{array}{l}\text { Ácido } \\
\text { bórico }\end{array}$ & $88,0 \mathrm{~A}$ & $93,2 \mathrm{~A}$ & $0,31 \mathrm{~A}$ & $63,7 \mathrm{~A}$ & $191,0 \mathrm{~A}$ & $22,7 \mathrm{~A}$ & $39,7 \mathrm{~A}$ & $35,0 \mathrm{~A}$ & $1.705,9 \mathrm{~A}$ \\
\hline Glyphosate & - & $92,5 \mathrm{~A}$ & $95,2 \mathrm{~A}$ & $0,20 \mathrm{~B}$ & $40,0 \mathrm{~B}$ & $187,5 \mathrm{~A}$ & $21,2 \mathrm{~A}$ & $39,6 \mathrm{~A}$ & $35,0 \mathrm{~A}$ & $1.523,1 \mathrm{~A}$ \\
\hline$\left(0,72\right.$ kg e.a. ha $\left.{ }^{-1}\right)$ & $\begin{array}{l}\text { Ácido } \\
\text { bórico }\end{array}$ & $91,0 \mathrm{~A}$ & $91,5 \mathrm{~A}$ & $0,33 \mathrm{~A}$ & $62,9 \mathrm{~A}$ & $193,7 \mathrm{~A}$ & $22,0 \mathrm{~A}$ & $38,6 \mathrm{~A}$ & $35,0 \mathrm{~A}$ & $1.708,1 \mathrm{~A}$ \\
\hline Glyphosate potássico & - & $91,2 \mathrm{~A}$ & $94,5 \mathrm{~A}$ & $0,18 \mathrm{~B}$ & $34,1 \mathrm{~B}$ & $184,3 \mathrm{~A}$ & $21,5 \mathrm{~A}$ & $39,2 \mathrm{~A}$ & $35,4 \mathrm{~A}$ & $1.571,4 \mathrm{~A}$ \\
\hline$\left(1,24 \mathrm{~kg}\right.$ i.a. $\left.\mathrm{ha}^{-1}\right)$ & $\begin{array}{l}\text { Ácido } \\
\text { bórico }\end{array}$ & $93,7 \mathrm{~A}$ & $97,2 \mathrm{~A}$ & $0,27 \mathrm{~A}$ & $53,9 \mathrm{~A}$ & $185,1 \mathrm{~A}$ & $21,8 \mathrm{~A}$ & $39,7 \mathrm{~A}$ & $35,4 \mathrm{~A}$ & $1.619,4 \mathrm{~A}$ \\
\hline Paraquat & - & $91,2 \mathrm{~A}$ & $93,7 \mathrm{~A}$ & $0,17 \mathrm{~B}$ & $34,8 \mathrm{~B}$ & $191,0 \mathrm{~A}$ & $22,2 \mathrm{~A}$ & $39,6 \mathrm{~A}$ & $35,8 \mathrm{~A}$ & $1.753,8 \mathrm{~A}$ \\
\hline$\left(0,4\right.$ kg i.a. $\left.\mathrm{ha}^{-1}\right)$ & $\begin{array}{l}\text { Ácido } \\
\text { bórico }\end{array}$ & $91,2 \mathrm{~A}$ & $90,0 \mathrm{~A}$ & $0,29 \mathrm{~A}$ & $55,7 \mathrm{~A}$ & $187,9 \mathrm{~A}$ & $21,9 \mathrm{~A}$ & $39,3 \mathrm{~A}$ & $35,3 \mathrm{~A}$ & $1.645,2 \mathrm{~A}$ \\
\hline Glyphosate + Flumioxazin & - & $93,7 \mathrm{~A}$ & $91,2 \mathrm{~B}$ & $0,15 \mathrm{~B}$ & $30,7 \mathrm{~B}$ & $185,9 \mathrm{~A}$ & $22,3 \mathrm{~A}$ & $40,8 \mathrm{~A}$ & $36,1 \mathrm{~A}$ & $1.628,8 \mathrm{~A}$ \\
\hline $0,72 \mathrm{~kg}$ e. a. ha ${ }^{-1}+0,025 \mathrm{~kg}$ i.a. ha ${ }^{-1}$ & $\begin{array}{l}\text { Ácido } \\
\text { bórico }\end{array}$ & $93,7 \mathrm{~A}$ & $96,0 \mathrm{~A}$ & $0,39 \mathrm{~A}$ & $55,9 \mathrm{~A}$ & 186,4 A & $22,1 \mathrm{~A}$ & $40,2 \mathrm{~A}$ & $35,2 \mathrm{~A}$ & $1.661,8 \mathrm{~A}$ \\
\hline Glyphosate + Carfentrazone & - & $93,7 \mathrm{~A}$ & $94,5 \mathrm{~A}$ & $0,16 \mathrm{~B}$ & $29,4 \mathrm{~B}$ & $181,5 \mathrm{~B}$ & $21,9 \mathrm{~A}$ & $39,5 \mathrm{~A}$ & $35,0 \mathrm{~A}$ & $1.554,7 \mathrm{~A}$ \\
\hline $0,72 \mathrm{~kg}$ e. a. $\mathrm{ha}^{-1}+0,02 \mathrm{~kg}$ i.a. ha ${ }^{-1}$ & $\begin{array}{l}\text { Ácido } \\
\text { bórico }\end{array}$ & $95,0 \mathrm{~A}$ & $97,2 \mathrm{~A}$ & $0,27 \mathrm{~A}$ & $58,9 \mathrm{~A}$ & $189,9 \mathrm{~A}$ & $21,5 \mathrm{~A}$ & $38,6 \mathrm{~A}$ & $35,4 \mathrm{~A}$ & $1.692,7 \mathrm{~A}$ \\
\hline \multirow[b]{2}{*}{ Testemunha capinada } & - & $100,0 \mathrm{~A}$ & $100,0 \mathrm{~A}$ & $0,19 \mathrm{~B}$ & $35,9 \mathrm{~B}$ & $186,5 \mathrm{~A}$ & $22,1 \mathrm{~A}$ & $38,9 \mathrm{~A}$ & $34,7 \mathrm{~A}$ & $1.617,5 \mathrm{~A}$ \\
\hline & $\begin{array}{l}\text { Ácido } \\
\text { bórico }\end{array}$ & $100,0 \mathrm{~A}$ & $100,0 \mathrm{~A}$ & $0,36 \mathrm{~A}$ & $46,2 \mathrm{~A}$ & $185,1 \mathrm{~A}$ & $22,5 \mathrm{~A}$ & $39,3 \mathrm{~A}$ & $35,1 \mathrm{~A}$ & $1.663,3 \mathrm{~A}$ \\
\hline \multirow[b]{2}{*}{ Testemunha sem capina } & - & $0,0 \mathrm{~A}$ & $0,0 \mathrm{~A}$ & $0,19 \mathrm{~B}$ & $26,1 \mathrm{~B}$ & $190,3 \mathrm{~A}$ & $21,1 \mathrm{~A}$ & $39,8 \mathrm{~A}$ & $35,0 \mathrm{~A}$ & $1.562,4 \mathrm{~A}$ \\
\hline & $\begin{array}{l}\text { Ácido } \\
\text { bórico }\end{array}$ & $0,0 \mathrm{~A}$ & $0,0 \mathrm{~A}$ & $0,34 \mathrm{~A}$ & $44,8 \mathrm{~A}$ & $191,8 \mathrm{~A}$ & $22,1 \mathrm{~A}$ & $39,7 \mathrm{~A}$ & $36,0 \mathrm{~A}$ & $1.765,0 \mathrm{~A}$ \\
\hline $\mathrm{CV}(\%)$ & & 2,5 & 3,1 & 20,9 & 14,8 & 2,3 & 4,5 & 3,5 & 2,0 & 9,3 \\
\hline
\end{tabular}

${ }^{1 /}$ Em cada coluna e para cada tratamento, as médias seguidas pelas mesmas letras não diferem entre si pelo teste de Tukey a $5 \%$ de probabilidade.

Pelos resultados obtidos neste trabalho, conclui-se que a adição de ácido bórico à calda de pulverização não prejudica o controle das plantas daninhas pelos tratamentos dessecantes, exceto para a mistura formulada de paraquat + diuron. Há aumento dos teores de boro no solo e nas folhas das culturas de soja e girassol quando o ácido bórico é associado aos herbicidas dessecantes. A aplicação conjunta de herbicidas dessecantes e ácido bórico é viável, controlando as plantas daninhas em pré-semeadura e aumentando o teor de boro no solo e nas plantas de soja e girassol.

\section{LITERATURA CITADA}

ASAD, A. Boron requirements for sunflower and wheat. J. Plant Nutr., v. 25, n. 4, p. 885-899, 2002.

ASAD, A.; BLAMEY, F. P. C.; EDWARDS, D. G. Dry matter production and boron concentrations of vegetative and reprodutive tissues of canola and sunflower plants grown in nutrient solution. Plant Soil, v. 243, n. 2, p. 243-252, 2002.
ASAD, A.; BLAMEY, F. P. C.; EDWARDS, D. G. Effects of boron foliar application on vegetative and reprodutive growth of sunflower. Ann. Bot., v. 92, n. 4, p. 565-570, 2003.

BEDMAR, F.; LEADEN, M.; EYHERABIDE, J. Efectos de la competencia de las malezas con el girasol. IX Reunión Argentina sobre la maleza y su control. ASAM, v. 11, n. 4, p. 51-61, 1983.

BLAMEY, F. P. C. Boron nutrition of sunflower (Helianthus annuus L.) on Avalon medium sandy loam.

Agrochemophysica, v. 8, n. 1, p. 5-10, 1976.

BLAMEY, F. P. C.; MOULD, D.; CHAPMAN, J. Critical boron concentrations in plant tissue of two sunflower cultivars. Agron. J., v. 71, n. 2, p. 243-247, 1979.

BLAMEY, F. P. C.; ZOLLINGER, R. K.; SCHNEITER, A. A. Sunflower production and culture. In: SCHNEITER, A. A. (Ed). Sunflower technology and production. Madison: American Society of Agronomy, 1997. p. 595-670, (Agronomy, 35). 
BRIGHENTI, A. M. et al. Associação de dessecantes e boro no manejo de plantas daninhas e na nutrição mineral da cultura do girassol (Helianthus annuиs). B. Inf. SBCPD, v. 10, p. 181-182, 2004.

BRIGHENTI, A. M. et al. Manejo de plantas daninhas no girassol. In: LEITE, R. M. V. B. C.; BRIGHENTI, A. M.; CASTRO, C. (Eds.). Girassol no Brasil. Londrina: Embrapa Soja, 2005. p. 411-469.

BOARETTO, A. E.; TIRITAN, C. S.; MURAOKA, T. Effects of foliar applications of boron on citrus fruit and on foliage and soil boron concentration. In: BELL, R. W.; RERKASEM, B. (Eds.). Boron in soils and plants. London: Kluwer Academic Publishers, 1997. p. 121-123.

CASTRO, C. Boro e estresse hídrico na nutrição e produção do girassol em casa-de-vegetação. 1999. $120 \mathrm{f}$. Tese (Doutorado em Agronomia) - Escola Superior de Agricultura "Luiz de Queiroz", Piracicaba, 1999.

CASTRO, C. et al. A cultura do girassol. Londrina: EMBRAPA - CNPSo, 1996. 36 p. (EMBRAPA - CNPSo. Circular Técnica, 13).

CASTRO, C.; OLIVEIRA, F. A. Nutrição e adubação do girassol. In: LEITE, R. M. V. B. C.; BRIGHENTI, A. M.; CASTRO, C. (Eds.). Girassol no Brasil. Londrina: Embrapa Soja, 2005. p. 317-373.

DENIS, M. H.; DELROT, S. Carrier-mediated uptake of glyphosate in broad bean (Vicia faba) via a phosphate transporter. Physiol. Plant., v. 87, n. 4, p. 569-575, 1993.

DIGGS, C. A.; RATTO DE MIGUEZ, M. S.; SHORROCKS, V. M. Boron deficiency symptoms evaluation: the most accurate method to decide sunflower boron fertilization. In: INTERNATIONAL SUNFLOWER CONFERENCE, 13., 1992, Pisa. Proceedings... Pisa: 1992. p. 8-10.

EPSTEIN, E.; BLOOM, A. J. Mineral nutrition of plants; principles and perspectives. Sunderland: Sinauer Associates, 2005. $400 \mathrm{p}$.

GOUGLER, J. A.; GEIGER, D. R. Uptake and distribution of N-phosphonomethylglycine in sugar beet plants. Plant Physiol., v. 68, n. 3, p. 668-672, 1981.

INCHEM. Data sheets on pesticides no 4 Rev. 1 Paraquat. Disponível em: <http://www.inchem.org/documents/pds/pds/ pest4_e.htm>. Acesso em: 1 jan. 2005.

LUCY, M. (Comp.). Fallow weed management... herbicides and water quality. Disponível em: <http:// www.dpi.qld.au/fieldcrops/8265.html>. Acesso em: 28 jan. 2005.
MACHADO, P. R. Absorção de nutrientes por duas variedades de girassol (Helianthus annuus $\mathbf{L}$.) em função da idade e adubação em condições de campo. 1979. $83 \mathrm{f}$. Dissertação (Mestrado em Agronomia) - Escola Superior de Agricultura “Luiz de Queiroz”, Piracicaba, 1979.

MARSCHNER, $\mathrm{H}$. Mineral nutrition of higher plants. 2.ed. London: Academic Press, 1995. 889 p.

MORTVEDT, J. J.; WOODRUFF, J. R. Technology and application of boron fertilizers for crops. In: GUPTA, U. C. Boron and its role in crop production. Boca Raton: CRC Press, 1993. p. 157-176.

MOTEKAITIS, R. J.; MARTELL, A. E. Metal chelate formation by N-phosphonomethylglycine and related ligands. J. Coord. Chem., v. 14, n. 2, p. 139-149, 1985.

ROSOLEM, C. A.; QUAGGIO, J. A.; SILVA, N. M. Algodão, amendoim e soja. In: FERREIRA, M. E. et al. (Eds.). Micronutrientes e elementos tóxicos na agricultura. Jaboticabal: CNPq/FAPESP/POTAFOS, 2001. p. $319-354$.

SARKER, S. K.; CHOWDHURY, M. A. H.; ZAKIR, H. M. Sulphur and boron fertilization on yield quality and nutrient uptake by Bangladesh Soybean-4. J. Biol. Sci., v. 2, n. 11, p. 729-733, 2002.

SILVA, F. R.; FERREYRA, H. F. Avaliação de extratores de boro em solos do estado do Ceará. R. Bras. Ci. Solo, v. 22, n. 3, p. 471-478, 1998.

STAHLMAN, P. W.; PHILLIPS, W. M. Effects of water quality and spray volume on glyphosate phytotoxicity. Weed Sci., v. 27, n. 1, p. 38-41, 1979.

STERLING, T. Mechanisms of herbicide absorption across plant membranes and accumulation in plant cells. Weed Sci., v. 42, n. 2, p. 263-276, 1994.

THELEN, K. D.; JACKSON, E. P.; PENNER, D. The basis for the hard-water antagonism of glyphosate activity. Weed Sci., v. 43, n. 4, p. 541-548, 1995.

TURNER, D. J.; LOADER, M. P. C. Complexing agents as herbicides additives. Weed Res., v. 18, n. 4, p. 199-207, 1978.

VIDAL, R. A.; MEROTTO Jr., A. Herbicidologia. Porto Alegre: Edição dos Autores, 2001. 152 p.

WAUCHOPE, D. Acid dissociation constants of arsenic acid, methylarsonic acid (MAA), dimethyl arsinic acid (cacodylic acid), and N-(phosphonomethyl)glycine (glyphosate). J. Agric. Food Chem., v. 24, n. 4, p.717-721, 1976. 